Article

\title{
Mycotoxigenic Potentials of Fusarium Species in Various Culture Matrices Revealed by Mycotoxin Profiling
}

\author{
Wen Shi ${ }^{1}$, Yanglan Tan ${ }^{2}$, Shuangxia Wang ${ }^{2}$, Donald M. Gardiner ${ }^{3}$, Sarah De Saeger ${ }^{4}$, \\ Yucai Liao ${ }^{5}$, Cheng Wang ${ }^{6}$, Yingying Fan ${ }^{6}$, Zhouping Wang ${ }^{1, *}$ and Aibo $\mathrm{Wu}^{2, *}$ \\ 1 State Key Laboratory of Food Science and Technology, School of Food Science and Technology, \\ Jiangnan University, Wuxi 214122, China; sw1596321@sina.com \\ 2 SIBS-UGENT-SJTU Joint Laboratory of Mycotoxin Research, Key Laboratory of Food Safety Research, \\ Institute for Nutritional Sciences, Shanghai Institutes for Biological Sciences, Chinese Academy of Sciences, \\ University of Chinese Academy of Sciences, 294 Taiyuan Road, Shanghai 200031, China; \\ yltan@sibs.ac.cn (Y.T.); shuangxiawang@163.com (S.W.) \\ 3 Commonwealth Scientific and Industrial Research Organisation (CSIRO), 306 Carmody Road, \\ St Lucia QLD 4067, Australia; Donald.Gardiner@csiro.au \\ 4 Laboratory of Food Analysis, Faculty of Pharmaceutical Sciences, Ghent University, \\ Ottergemsesteenweg 460, Gent 9000, Belgium; Sarah.DeSaeger@UGent.be \\ 5 College of Plant Science and Technology, Huazhong Agricultural University, Wuhan 430000, China; \\ yucailiao@mail.hzau.edu.cn \\ 6 Institute of Quality Standards \& Testing Technology for Agro-Products, Laboratory of Quality and Safety \\ Risk Assessment for Agro-Products (Urumqi), Ministry of Agriculture, Xinjiang Academy of \\ Agricultural Sciences, 403 Nanchang Road, Urumqi 830091, China; wangcheng312@sina.com (C.W.); \\ fyyxaas@sina.com (Y.F.) \\ * $\quad$ Correspondence: wangzp@jiangnan.edu.cn (Z.W.); abwu@sibs.ac.cn (A.W.); \\ Tel.: +86-510-8532-6195 (Z.W.); +86-21-5492-0716 (A.W.)
}

Academic Editor: Antonio Moretti Received: 31 August 2016; Accepted: 21 December 2016; Published: 26 December 2016

\begin{abstract}
In this study, twenty of the most common Fusarium species were molecularly characterized and inoculated on potato dextrose agar (PDA), rice and maize medium, where thirty three targeted mycotoxins, which might be the secondary metabolites of the identified fungal species, were detected by liquid chromatography-tandem mass spectrometry (LC-MS/MS). Statistical analysis was performed with principal component analysis (PCA) to characterize the mycotoxin profiles for the twenty fungi, suggesting that these fungi species could be discriminated and divided into three groups as follows. Group I, the fusaric acid producers, were defined into two subgroups, namely subgroup I as producers of fusaric acid and fumonisins, comprising of F. proliferatum, F. verticillioides, F. fujikuroi and F. solani, and subgroup II considered to only produce fusaric acid, including F. temperatum, F. subglutinans, F. musae, F. tricinctum, F. oxysporum, F. equiseti, F. sacchari, F. concentricum, F. andiyazi. Group II, as type A trichothecenes producers, included F. langsethiae, F. sporotrichioides, F. polyphialidicum, while Group III were found to mainly produce type B trichothecenes, comprising of F. culmorum, F. poae, F. meridionale and F. graminearum. A comprehensive picture, which presents the mycotoxin-producing patterns by the selected fungal species in various matrices, is obtained for the first time, and thus from an application point of view, provides key information to explore mycotoxigenic potentials of Fusarium species and forecast the Fusarium infestation/mycotoxins contamination.
\end{abstract}

Keywords: Fusarium fungi; mycotoxin profiles; principal component analysis; culture substrates 


\section{Introduction}

Fusarium spp. are a large complex genus, known as worldwide plant pathogens which infect and colonize various cereal crops such as maize, rice, wheat and oats in temperate and semi-tropical areas, including China, North America, South Africa and all European cereal-growing areas [1-5]. Fusarium spp. have been found to cause significant reduction in quality and yield in many food and feed crops, estimated at between $10 \%$ and $30 \%$. The worst affected crops are wheat, maize and rice, where Fusarium spp. are known to cause Fusarium head blight (FHB) of wheat, sheath rot disease of maize and bakanae disease of rice [6-9].

The widespread presence of fungi and mycotoxins in pre-harvest infected plants or in-store grains are of great concern for human and animal health. The most occurring Fusarium mycotoxins are deoxynivalenol (DON), 3-acetyl deoxynivalenol (3-ADON), 15-acetyl deoxynivalenol (15-ADON), nivalenol (NIV) and fusarenon X (Fus-X); T-2 toxin, HT-2 toxin, neosolaniol (NEO) and diacetoxyscirpenol (DAS); zearalenone (ZEN), fumonisin B1 (FB1), fumonisin B2 (FB2) and fusaric acid [10-15]. Acute and chronic exposure to these mycotoxins exhibits various toxic effects to plants and animals, and poses a potential health risk for humans [16,17]. Due to the high toxicity and worldwide occurrence of the mycotoxins, maximum levels concerning some major mycotoxins have been set in the European countries [18] and also in China [19].

The phase of maize fusariosis with the highest toxicological concern is the ear rot, but large amounts of mycotoxins can also be formed in infected leaves (NIV), rotted stalks (notably ZEN and DON) and whole plants (ZEN) [20]. The variability in the fungal strains is an important issue for food safety, as multiple mycotoxins with different toxicities could be produced. So far, the risks of combined toxicity have been poorly understood, but generally it can be concluded that co-exposure to several different mycotoxins often results in synergistic effects [21]. In addition, the matrix significantly influences the toxin-producing abilities of the mycotoxigenic fungi, leading to complex mycotoxin contamination situations. Therefore, it is a critical issue to investigate the mycotoxin profiles and reveal mycotoxigenic potentials of various Fusarium spp. in different substrates.

Several studies have been performed to investigate the relationship between Fusarium spp. and mycotoxin production. In Germany, as well as in many other central European countries, F. graminearum is the predominant Fusarium fungi in wheat followed by F. culmorum, both of which have been associated with occurrence of ZEN and DON in wheat and other crops [22,23]. In China, 3-ADON, 15-ADON and NIV are the main mycotoxins produced by F. graminearum isolated from wheat ears with clear FHB symptoms [24]. Several other surveys also suggested that F. solani, F. graminearum and F. sambucinum could produce one or more mycotoxins, such as DON in north-central United States [25] and ZEN, NIV, 15-ADON in Argentina [12,26]. However, most of the studies only focused on the main important Fusarium fungi isolated from cereal grains, with very little attention paid to other fungal species, such as Fusarium musae, Fusarium fujikuroi, Fusarium concentricum, Fusarium lateritium, Fusarium incarnatum-equiseti, Fusarium meridionale and Fusarium polyphialidicum. This study therefore took in account the less studied species for the following reasons: (1) they play an important role in spoilage of grain cereals during storage and marketing; (2) these Fusarium species can potentially produce mycotoxins in maize and rice matrices even though they were isolated from other substrates such as banana, green pepper and barley. No previous attempts have been made to study the distributions of all frequently occurring mycotoxins (such as ZEN and its derivatives, type B trichothecenes, type A trichothecenes, FB1, FB2 and fusaric acid), along with some other less studied Fusarium metabolites produced by various Fusarium spp.

The major focus of this study is to thoroughly investigate the mycotoxin-producing capabilities of twenty Fusarium species in different culture substrates. A definitive understanding of the prevalence of Fusarium spp. and their associated mycotoxigenic potential is not only critical for the development of strategies for monitoring and managing mycotoxin contamination, but also to obtain a precise picture of the toxicological risks related to maize and rice consumption by humans and animals. 


\section{Results and Discussion}

\subsection{Molecular Characterization of Fusarium Species}

The electrophoresis chromatograms of the EF-1 $\alpha$ gene from twenty strains (Table 1) collected from different areas are shown in Figure 1A. The single band observed for all the selected strains demonstrated the purity of the fungi and the species to be Fusarium strains.

The phylogenetic tree constructed based on EF-1 $\alpha$ gene is shown in Figure 1B. After comparison of the targeted gene sequences with the standard sequences in GenBank, the identity of all the Fusarium strains was clearly confirmed since the similarities of the sequence between the targeted fungi and the standard one were equal to or above $96 \%$.

Table 1. The information of the Fusarium strains used in this study.

\begin{tabular}{ccccc}
\hline Strain No. & Code & Fusarium Species & Origin & Host \\
\hline 1 & MUCL 152463 & Fusarium temperatum & Belgium & Maize \\
2 & MUCL 43485 & Fusarium subglutinans & United States & Maize \\
3 & MUCL 42823 & Fusarium culmorum & Belgium & Wheat \\
4 & MUCL 51036 & Fusarium fujikuroi & Philippines & Rice \\
5 & MUCL 34988 & Fusarium langsethiae & - & Wheat \\
6 & MUCL 52574 & Fusarium musae & Honduras & Banana \\
7 & MUCL 53395 & Fusarium poae & Belgium & Maize \\
8 & MUCL 43483 & Fusarium proliferatum & - & - \\
9 & F-1 & Fusarium graminearum & China & Wheat \\
10 & MUCL 53602 & Fusarium sporotrichioides & Belgium & Maize \\
11 & MUCL 42821 & Fusarium tricinctum & Belgium & Wheat \\
12 & MUCL 43478 & Fusarium verticillioides & United States & Maize \\
13 & B40= F50/1-i1-B & Fusarium oxysporum & China & Barley \\
14 & MC1_30 & Fusarium meridionale & China & Maize \\
15 & M-12-0203-A1 & Fusarium equiseti & China & Maize \\
16 & M-12-0501-J1 & Fusarium sacchari & China & Maize \\
17 & M-12-0601-D12 & Fusarium solani & China & Maize \\
18 & Q29 & Fusarium concentricum & China & Green pepper \\
19 & W21 & Fusarium andiyazi & China & Maize \\
20 & XB4-1 & Fusarium polyphialidicum & China & Barley \\
\hline
\end{tabular}

${ }^{1}$ MUCL Mycothèque de l'Université catholique de Louvain (Louvain-la-Neuve, Belgium).

\subsection{Applicability of LC-MS/MS Method}

The utilized LC-MS/MS method was established for simultaneous determination of multiple mycotoxins in Lentinula edodes in the previous study, and its applicability on PDA, rice and maize was validated. In the present study, the recoveries at concentration levels of $50 \mu \mathrm{g} \cdot \mathrm{kg}^{-1}$ for all mycotoxins spiked into each sample were tested. The experiment was done in quintuplicate. The results showed that satisfactory recoveries with mean values in the range of $72.5 \%-119.8 \%$ in PDA, $72.5 \%-119.5 \%$ in rice and $72.3 \%-119.6 \%$ in maize were obtained for all 33 mycotoxins (Table S1), verifying the suitability of the method employed for determination of the targeted mycotoxins in the above matrices. MRM chromatograms of mycotoxins detected in the media by the selected Fusarium species are presented in Figures S1-S4, showing that these mycotoxins can be identified by their retention times and two selective monitoring transitions. 

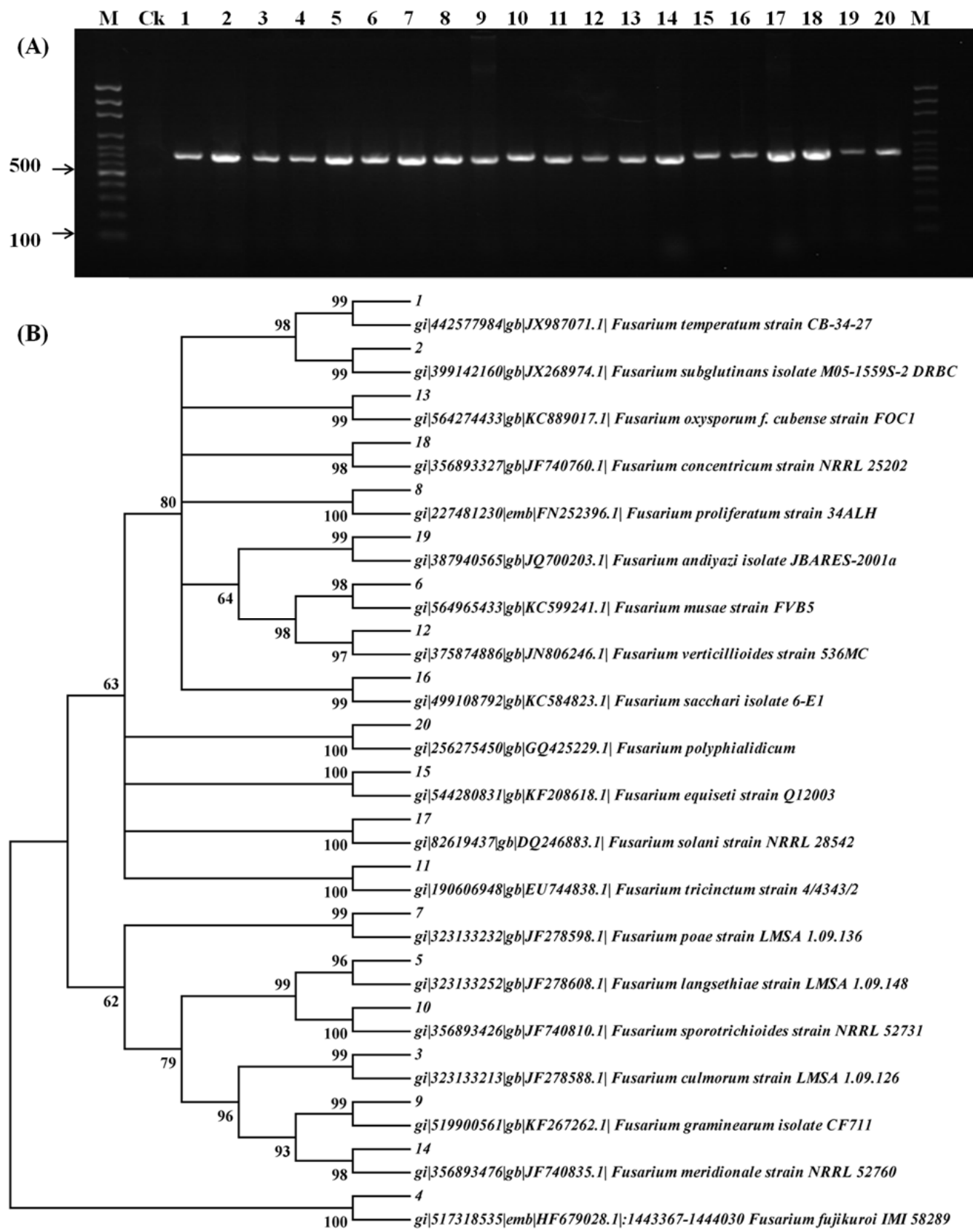

Figure 1. Electrophoresis chromatographs of the $E F-1 \alpha$ gene from different purified Fusarium strains (A) and subsequently constructed phylogenetic tree; (B). M indicates the 100-bp molecular marker; CK indicates negative control; 1-20 indicates the Fusarium strains as described in Table 1.

\subsection{Principal Component Analysis}

Mycotoxin production of Fusarium species are influenced greatly by culture conditions [27-29]. For instant, too high or low temperature showed inhibition of toxin biosynthesis [28] and thus the appropriate temperature such as $25{ }^{\circ} \mathrm{C}$ was adopted in some of related in vitro experiments when investigating multiple Fusarium species [30,31]. The temperature effects on mycotoxin production (PDA, 21 days) were initially evaluated between $5{ }^{\circ} \mathrm{C}$ and $40{ }^{\circ} \mathrm{C}$ in our study, and the results indicated that the sensitivity to temperature varied for different Fusarium species. Given that the optimum temperature for majority of the investigated twenty species ranged from $20^{\circ} \mathrm{C}$ to $30^{\circ} \mathrm{C}$ (results shown in Table S2), $25^{\circ} \mathrm{C}$ was chosen and kept constant for the following experiments. The culture medium 
is also the predominant effect on mycotoxin production by fungi, such as carbohydrate and nitrogen sources [30,32]. Previous reports showed that the carbohydrate-rich media were apparently more favorable for toxin producing [30,33], which was consistent with our results that significantly more mycotoxins were observed in rice and maize media than those in PDA medium (Tables S3-S5), except fusaric acid produced with highest abundance by some of Fusarium species on PDA medium. In order to further investigate the mycotoxigenic abilities of various Fusarium species on different culture media, PCA was carried out to classify the Fusarium strains based on their mycotoxin production. The score plots including PC1 (direction of largest variance) and PC2 (perpendicular to PC1 and against the largest variance) were extracted from the first two principal components, which presented the maximum variability in the data and made it easier to visually discriminate the differences [34]. The value of the loading plot reflects the contribution of each variable to the sample classification in the PCA. The farther from the origin a variable is placed, the higher contribution of that variable made to the PCA model [35].

In this study, thirteen mycotoxins were detected in the growth media by selected Fusarium species and then set as the variables for evaluation. As shown in Figure 2, the first principal component (PC1) and the second principal component (PC2) accounted for $67.22 \%$ and $25.82 \%$ of the variation for PDA (Figure 2A1), 68.46\% and 23.20\% for rice medium (Figure 2B1), $72.29 \%$ and $23.94 \%$ for maize medium (Figure 2C1), respectively. It could be obviously seen that for all the above three culture media the cumulative variance contribution of PC1 and PC2 was more than $90 \%$, proving the significant variability of mycotoxin profiles of different Fusarium strains studied.

For PDA medium (Figure 2A2), fusaric acid correlated positively with PC1 while the fumonisins (FB1 and FB2) correlated negatively, indicating the critical role of these three mycotoxins in the differentiation of the Fusarium strains. Type A trichothecenes (T-2 toxin, HT-2 toxin, NEO and DAS) contribute negatively to PC1, but act as significantly positive contributors for PC2, verifying the important role of these four mycotoxins in further discrimination of the Fusarium strains. Similarly, the contributors for PC1 for rice medium (Figure 2B2) were fusaric acid, three type A trichothecenes (T-2 toxin, HT-2 toxin and NEO) and fumonisins (FB1 and FB2) while NIV, Fus-X and DAS contributed for PC2. In regard to maize medium, fusaric acid, type A trichothecenes (T-2 toxin, HT-2 toxin, DAS and NEO) and fumonisins (FB1 and FB2) contributed significantly to PC1, and NIV and Fus-X were the contributors for PC2 (Figure 2C2). Based on the mycotoxin profiles in PCA factor loading plots, the detected mycotoxins were divided into three major groups, including the Group I for fusaric acid, which could be subsequently divided into subgroup I for co-occurrence of fusaric acid and fumonisins (FB1 and FB2) and subgroup II for fusaric acid only, Group II for type A trichothecenes (T-2, HT-2, NEO, DAS) and Group III for type B trichothecenes (DON, 15-ADON, 3-ADON, NIV, Fus-X). Consequently, the targeted twenty toxigenic Fusarium fungal strains were grouped as shown in Table 2. The mycotoxin profiles of representative strains (F. proliferatum (A) for Group I, F. langsethiae (B) for Group II, and F. graminearum (C) and F. meridionale (D) for Group III) in each group cultivated on PDA, maize and rice medium are shown in Figure 3.

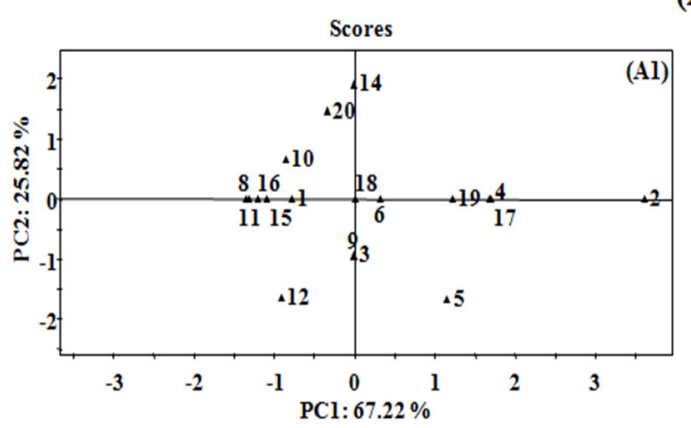

(A)

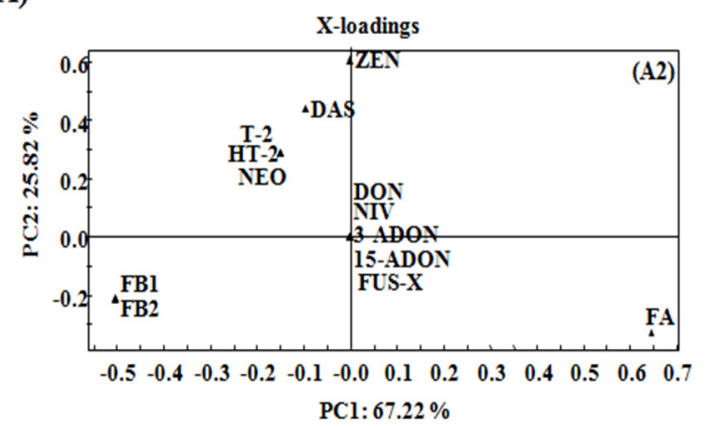

Figure 2. Cont. 
(B)
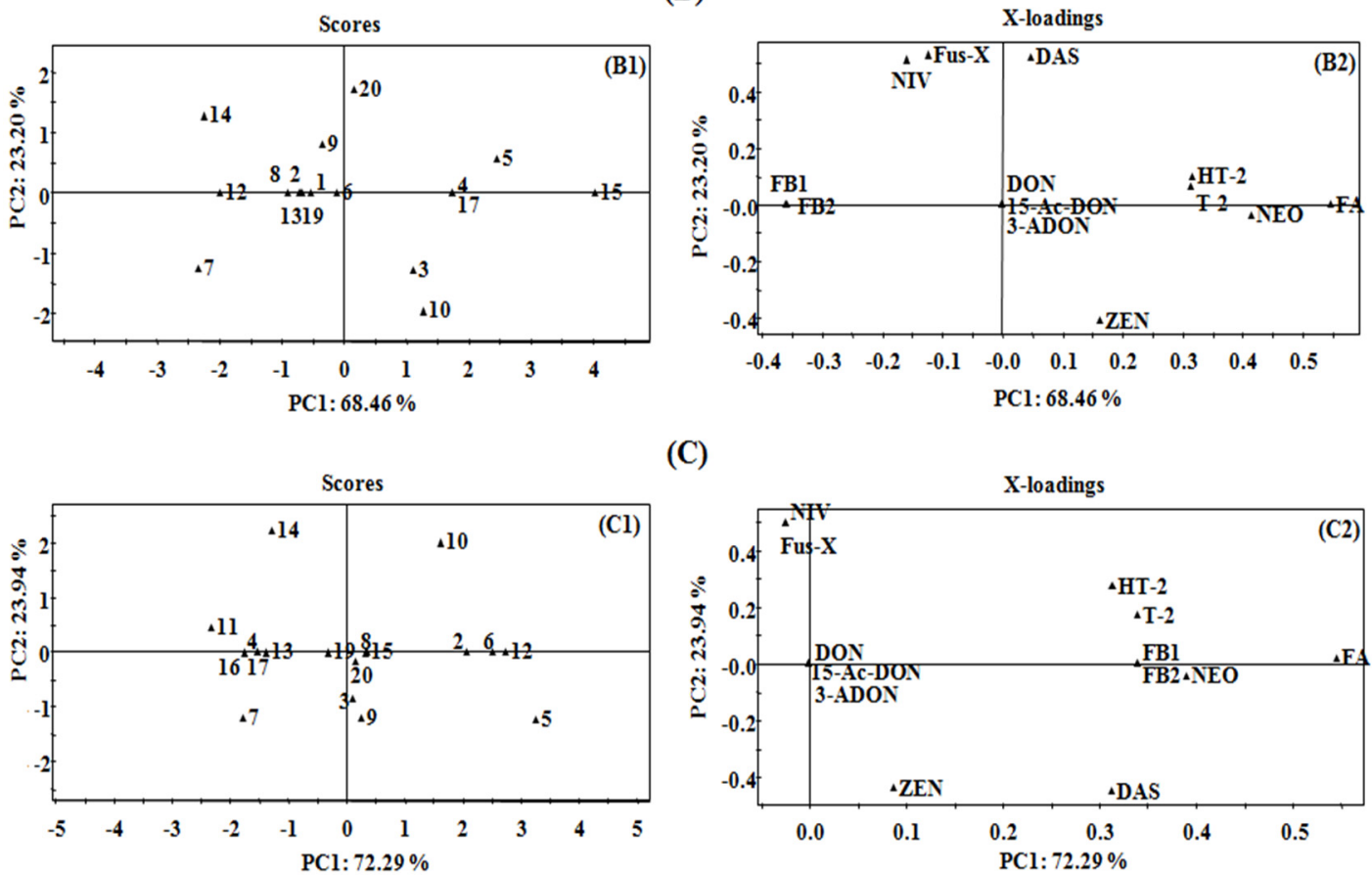

(C)

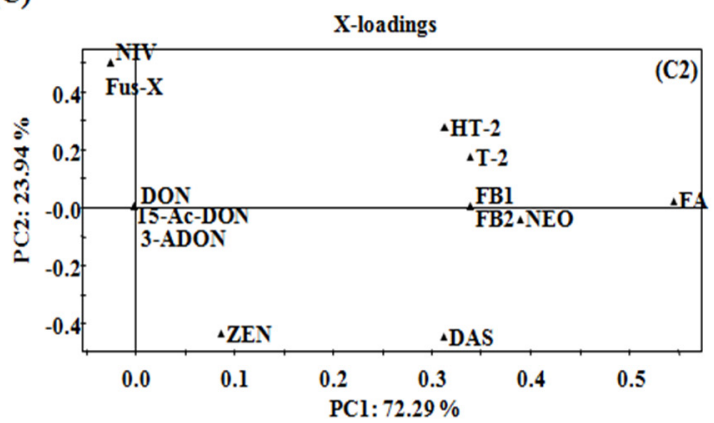

Figure 2. Statistical results of principal component analysis (PCA) of the detected mycotoxins by twenty Fusarium species in PDA (A), rice (B) and maize (C) medium. (A1), (B1) and (C1) on the left refer to the score plots showing the locations of the Fusarium species; (A2), (B2) and (C2) on the right were designed to the loading plot interpreting the relationships between mycotoxins produced by Fusarium species.

(A)

PDA

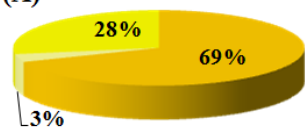

(B)

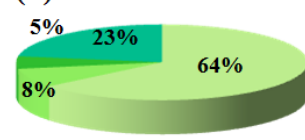

(C)

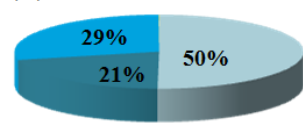

(D)

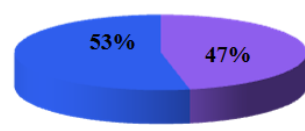

Rice
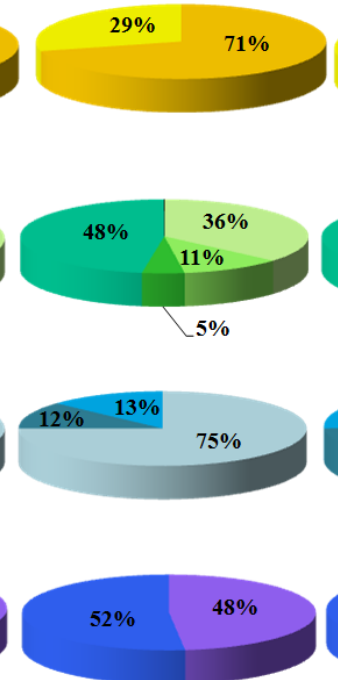

\section{Maize}
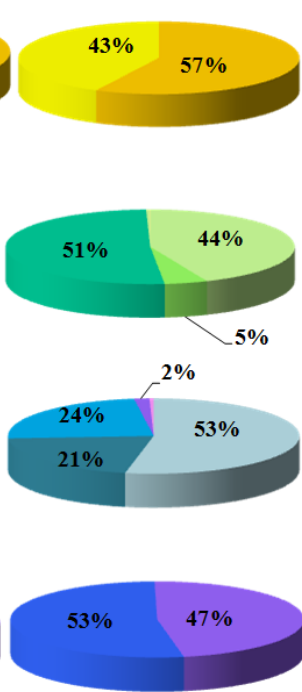

Fusaric acid

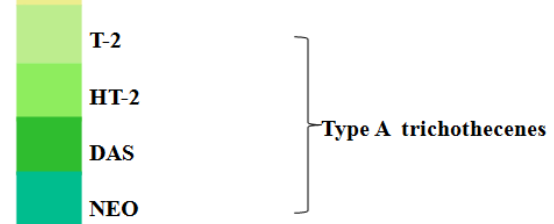

NEO

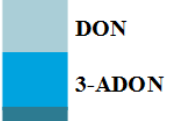

15-ADON

NIV

Fus-X

Figure 3. Pie charts of mycotoxin profiling produced by 4 representative Fusarium species including F. proliferatum (A), F. langsethiae (B), F. graminearum (C) and F. meridionale (D) in PDA, rice and maize medium. 
Table 2. Grouping of mycotoxigenic Fusarium species using mycotoxin profiles.

\begin{tabular}{|c|c|c|c|c|c|}
\hline \multicolumn{2}{|c|}{ Group } & \multirow{2}{*}{$\begin{array}{c}\text { Strain No. } \\
8\end{array}$} & \multirow{2}{*}{$\begin{array}{c}\text { Fusarium Species } \\
\text { F. proliferatum }\end{array}$} & \multirow{2}{*}{$\begin{array}{c}\begin{array}{c}\text { Major Mycotoxins } \\
\text { Produced }\end{array} \\
\text { FB1, FB2, Fusaric acid }\end{array}$} & \multirow{2}{*}{$\begin{array}{c}\text { Other Mycotoxins } \\
\text { Produced }\end{array}$} \\
\hline \multirow{13}{*}{$\begin{array}{c}\text { Group I } \\
\text { (Fusaric acid) }\end{array}$} & \multirow{4}{*}{$\begin{array}{c}\text { Subgroup I } \\
\text { (Fumonisins and } \\
\text { fusaric acid) }\end{array}$} & & & & \\
\hline & & 12 & F. verticillioides & FB1, FB2, Fusaric acid & - \\
\hline & & 4 & F. fujikuroi & FB1, FB2, Fusaric acid & - \\
\hline & & 17 & F. solani & FB1, FB2, Fusaric acid & - \\
\hline & \multirow{9}{*}{$\begin{array}{c}\text { Subgroup II } \\
\text { (Fusaric acid only) }\end{array}$} & 1 & F. temperatum & Fusaric acid & - \\
\hline & & 2 & F. subglutinans & Fusaric acid & - \\
\hline & & 6 & F. musae & Fusaric acid & - \\
\hline & & 11 & F. tricinctum & Fusaric acid & - \\
\hline & & 13 & F. oxysporum & Fusaric acid & - \\
\hline & & 15 & F. equiseti & Fusaric acid & - \\
\hline & & 16 & F. sacchari & Fusaric acid & - \\
\hline & & 18 & F. concentricum & Fusaric acid & - \\
\hline & & 19 & F. andiyazi & Fusaric acid & - \\
\hline \multirow{3}{*}{\multicolumn{2}{|c|}{ Group II (Type A trichothecenes) }} & 5 & F. langsethiae & T-2, HT-2, NEO, DAS & - \\
\hline & & 10 & F. sporotrichioides & T-2, HT-2, NEO, DAS & - \\
\hline & & 20 & F. polyphialidicum & DAS & - \\
\hline \multirow{4}{*}{\multicolumn{2}{|c|}{ Group III (Type B trichothecenes) }} & 3 & F. culmorum & NIV, Fus-X & T-2, HT-2, NEO, ZEN \\
\hline & & 7 & F. poae & NIV, Fus-X & T-2, HT-2, NEO, DAS \\
\hline & & 14 & F. meridionale & NIV, Fus-X & NEO, ZEN \\
\hline & & 9 & F. graminearum & DON, 15-ADON, 3-ADON & ZEN \\
\hline
\end{tabular}

\subsection{Mycotoxin-Producing Capacities of Fusarium Species in Different Growth Media}

\subsubsection{Group I/Fusaric Acid Producers}

Thirteen Fusarium strains, including F. proliferatum, F. verticillioides, F. fujikuroi, F. solani, F. temperatum, F. subglutinans, F. musae, F. tricinctum, F. oxysporum, F. equiseti, F. sacchari, F. concentricum and $F$. andiyazi, belonged to Group I due to their fusaric acid producing abilities. Among them, F. proliferatum, F. verticillioides, F. fujikuroi and F. solani belonged to subgroup I as producers of both fumonisins and fusaric acid, and the other nine Fusarium species were considered to merely produce fusaric acid (Table 2).

F. proliferatum and F. verticillioides are the major fumonisin producers with average concentrations for FB1 being 10,085 and 15,168 $\mu \mathrm{g} \cdot \mathrm{kg}^{-1}$ in PDA, 146,726 and 273,894 $\mu \mathrm{g} \cdot \mathrm{kg}^{-1}$ in rice and 104,810 and $237,208 \mu \mathrm{g} \cdot \mathrm{kg}^{-1}$ in maize medium, while the average concentrations for FB2 were 354 and $594 \mu \mathrm{g} \cdot \mathrm{kg}^{-1}$ on PDA, 60,378 and $98,523 \mu \mathrm{g} \cdot \mathrm{kg}^{-1}$ on rice, 77,939 and $180,778 \mu \mathrm{g} \cdot \mathrm{kg}^{-1}$ on maize, respectively (Tables S3-S5 and Figure 4). The high mycotoxin-producing abilities of these two Fusarium species found in this study are in good agreement with the previous studies [36,37]. F. fujikuroi produced fumonisins as well, but showed much lower concentration levels with values less than $200 \mu \mathrm{g} \cdot \mathrm{kg}^{-1}$ on all the three media, the mycotoxigenic potential of which have been reported to be greatly dependent on the isolated hosts and inoculation conditions [36,38]. Meanwhile, this is the first report about fumonisin production by F. solani.

With regard to the individual mycotoxin, relatively higher contents of FB1 were generated compared to FB2 by the same fungi on the three media (Figures $3 \mathrm{~A}$ and 4), which have been reported previously [33,39]. The ratios between the two fumonisins (FB1/FB2) for F. fujikuroi and F. solani were in the range of 1.4-3.1 in all media, but particularly 25.5 and 28.5 in PDA for F. verticillioides and F. proliferatum, respectively. As expected, the amounts of fumonisins produced in maize and rice were relatively higher than that in PDA, proving the influential role of the composition in different media in fumonisin-producing capabilities of Fusarium strains [40,41]. Fusaric acid were also detected with the above four Fusarium fungi but the amount was lower than that of fumonisins. 
Nine Fusarium strains were found to only produce fusaric acid in our study at average concentration levels ranging from 15 to $12,435 \mu \mathrm{g} \cdot \mathrm{kg}^{-1}$ (Tables S3-S5), and the production levels in PDA were higher than that in rice and maize media especially for F. subglutinans, F. musae, F. concentricum and F. andiyazi. In previous studies, F. sacchari and F. andiyazi were detected to produce low amounts of fumonisin $[42,43]$. Note that $F$. equiseti was considered as trichothecene producer (DON, 15-ADON, NIV, FUS-X, HT-2 and DAS) [31,44], but it showed a considerable intraspecies variation in profiles of trichothecene production, and even trichothecenes were not observed with some isolates of $F$. equiseti [45].

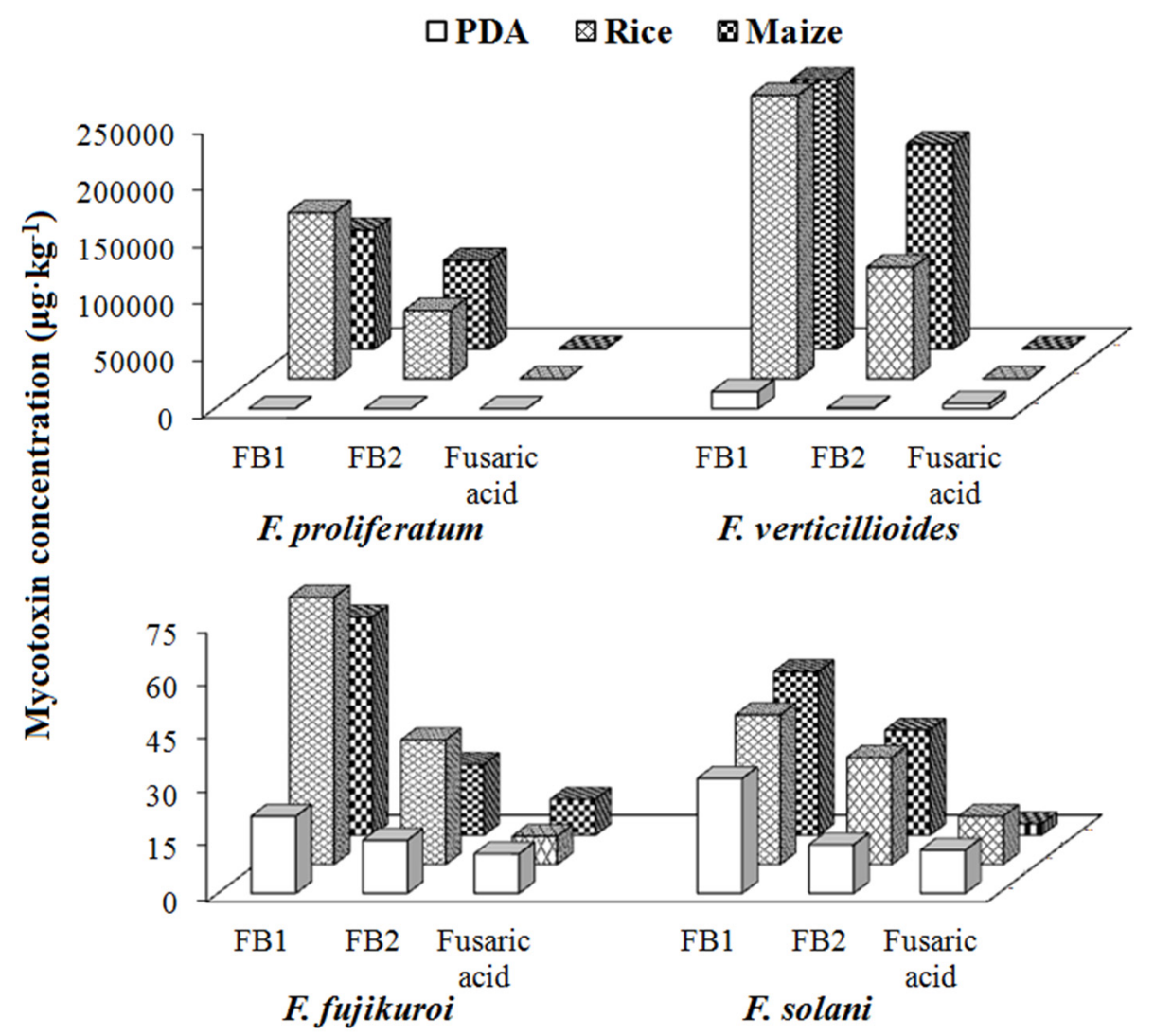

Figure 4. Investigation of the fumonisin B1 (FB1), fumonisin B2 (FB2) and fusaric acid producing abilities of F. proliferatum, F. verticillioides, F. fujikuroi and F. solani after incubation for 21 days at $25^{\circ} \mathrm{C}$ on PDA, rice and maize media.

\subsubsection{Group II/Type A Trichothecene Producers}

Group II was defined as type A trichothecene producer including F. langsethiae, F. sporotrichioides and F. polyphialidicum, which mainly produced one or several of type A trichothecenes, such as T-2, HT-2, NEO and DAS (Table 2).

Among the Group II Fusarium strains, F. langsethiae and F. sporotrichioides were found to be prolific producers of T-2, which was also demonstrated in Kokkonen et al.'s studies [27,30]. In general, high concentrations of T-2, NEO, and low production of HT-2 and DAS were observed for all the studied substrates (Tables S3-S5, Figures 3B and 5). These results were consistent with the results from Yli-Mattila et al., reporting that $F$. langsethiae and F. sporotrichioides produced high levels of T-2 with mean concentrations about $21,700-38,600 \mu \mathrm{g} \cdot \mathrm{kg}^{-1}$, and low mean concentrations of DAS with 90-2800 $\mu \mathrm{g} \cdot \mathrm{kg}^{-1}$ [46]. With respect to F. polyphialidicum, it appeared to be a rare Fusarium species isolated from plant debris collected in South Africa [47], and the mycotoxin producing abilities have been only limitedly investigated up to date, reporting it as FB1 producer [48]. In this study, DAS was found to be produced by this fungus for the first time with mean concentration levels of 23, 1333 and 
$3386 \mu \mathrm{g} \cdot \mathrm{kg}^{-1}$ in PDA, rice and maize medium, respectively (Tables S3-S5). Additionally, it could be obviously seen that for Group II fungi (Type A trichothecene producers), the highest concentrations of various mycotoxins were produced in maize, followed by rice, and lowest values were observed in PDA.

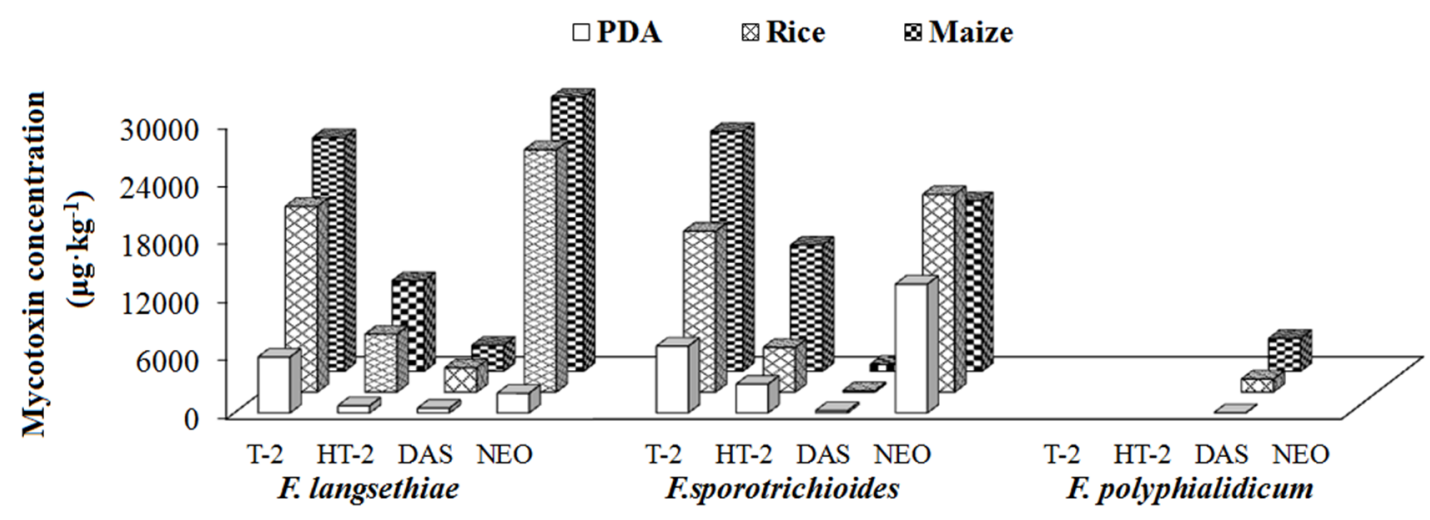

Figure 5. Investigation of the type A trichothecene mycotoxins (T-2, HT-2, NEO and DAS) producing abilities of F. langsethiae, F. sporotrichioides and F. polyphialidicum after incubation for 21 days at $25^{\circ} \mathrm{C}$ on PDA, rice and maize media.

\subsubsection{Group III/Type B Trichothecene Producers}

The concentrations of NIV and Fus-X were 269 and $13 \mu \mathrm{g} \cdot \mathrm{kg}^{-1}$ in PDA, 3151 and $1022 \mu \mathrm{g} \cdot \mathrm{kg}^{-1}$ in rice, 2039 and $1260 \mu \mathrm{g} \cdot \mathrm{kg}^{-1}$ in maize produced by F. culmorum; 566 and $60 \mu \mathrm{g} \cdot \mathrm{kg}^{-1}$ in PDA, 21,231 and $1838 \mu \mathrm{g} \cdot \mathrm{kg}^{-1}$ in rice, 979 and $137 \mu \mathrm{g} \cdot \mathrm{kg}^{-1}$ in maize produced by F. poae; 123 and $107 \mu \mathrm{g} \cdot \mathrm{kg}^{-1}$ in PDA, 120,342 and $112,167 \mu \mathrm{g} \cdot \mathrm{kg}^{-1}$ in rice, 45,453 and $37,175 \mu \mathrm{g} \cdot \mathrm{kg}^{-1}$ in maize produced by $F$. meridionale, respectively (Tables S3-S5, Figure 6). F. poae and F. culmorum have previously been considered as good producers for NIV and Fus-X [49-51]. In the present study, F. graminearum produced large amounts of DON, 3-ADON and 15-ADON, with concentration levels in PDA, rice and maize media in the range of $13,532-286,258 \mu \mathrm{g} \cdot \mathrm{kg}^{-1}, 7700-50,344 \mu \mathrm{g} \cdot \mathrm{kg}^{-1}$ and $5716-44,943 \mu \mathrm{g} \cdot \mathrm{kg}^{-1}$, respectively (Tables S3-S5, Figure 6). In previous studies, two type B trichothecence producing chemotypes were identified, i.e., the NIV and DON chemotypes [52-54]. Based on the results of this study, F. culmorum, F. poae and F. meridionale can be grouped into the NIV chemotype, while F. graminearum could be classified into the DON chemotype (Table 2).

Another feature with Group III is the co-occurrence of multiple types of mycotoxins in rice and maize media. As consistent with previous in vitro results, ZEN was produced by F. culmorum [27,31], F. meridionale [1] and F. graminearum [27,31] with highest levels herein in rice media. Previous studies indicated that F. culmorum showed intraspecies differences in the production of trichothecenes [45]. In our experiments, type A trichothecenes were detected in rice and maize media with F. culmorum, as well as F. poae and F. meridionale, especially significant amount of DAS produced by F. poae. 


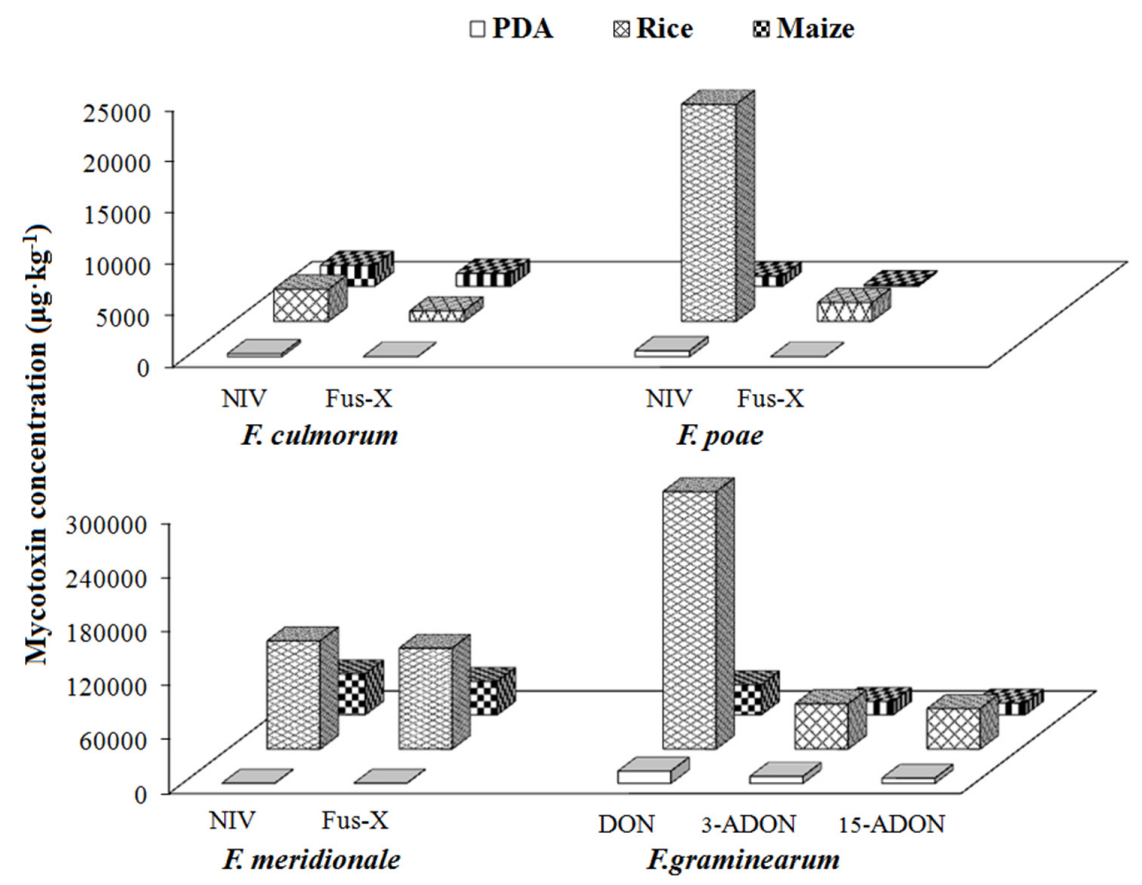

Figure 6. Investigation of the type B trichothecene mycotoxins (NIV, Fus- $X, D O N, 3-A D O N$ and 15-ADON) producing abilities of F. culmorum, F. poae, F. meridionale and F. graminearum after incubation for 21 days at $25^{\circ} \mathrm{C}$ on PDA, rice and maize media.

\section{Conclusions}

Twenty Fusarium species isolated from different regions were identified by molecular approaches and then inoculated on three growth media, PDA, rice and maize. The produced mycotoxins were determined quantitatively by LC-MS/MS and results were statistically analyzed using PCA. Fusarium species were accordingly divided into three groups, and mycotoxin profiles were thoroughly investigated to provide the direct evidences for clarification of the correlation between different mycotoxigenic fungi, mycotoxins and growth media. The targeted mycotoxin profiling in this study revealed mycotoxigenic potentials of Fusarium species in various culture substrates, which would contribute to further research concerning mycotoxin analysis and fungal investigations, as well as provide supporting information for controlling occurrence of fungi and their metabolic mycotoxins from farm to fork to ensure public health safety.

\section{Materials and Methods}

\subsection{Fungal Strains, Materials and Chemicals}

Twenty strains of Fusarium fungi were used in this study. F. temperatum, F. subglutinans, F. culmorum, F. fujikuroi, F. langsethiae, F. musae, F. poae, F. proliferatum, F. sporotrichioides, F. tricinctum and $F$. verticillioides were provided by Mycothèque de l'Université catholique de Louvain (MUCL, Louvain-la-Neuve, Belgium). The other nine Fusarium strains, including F. graminearum, F. oxysporum, F. meridionale, F. equiseti, F. sacchari, F. solani, F. concentricum, F. andiyazi, and F. polyphialidicum, were obtained by single spore isolation in our laboratory. Information about geographical location and plant hosts of all the investigated fungal species are presented in Table 1. Cereal matrices used for preparation of rice and maize medium were purchased from local suppliers, which were all mycotoxins-free as confirmed by liquid chromatography-tandem mass spectrometry (LC-MS/MS).

The mycotoxin standards of aflatoxin B1 (AFB1), aflatoxin B2 (AFB2), aflatoxin G1 (AFG1), aflatoxin G2 (AFG2), aflatoxin M1 (AFM1), aflatoxin M2 (AFM2), HT-2 toxin, T-2 toxin and ochratoxin 
A (OTA) were supplied by Alexisa (San Diego, CA, USA). 15-ADON and 3-ADON were purchased from Biopure (Tulln, Austria). Fusaric acid, ZEN, zearalanone (ZAN), $\alpha$-zearalenol ( $\alpha$-ZEL), $\alpha$-zearalanol $(\alpha$-ZAL), $\beta$-zearalenol ( $\beta$-ZEL), $\beta$-zearalanol ( $\beta$-ZAL), DON, NIV, deepoxy-DON, sterigmatocystin (SMC), Fus- $X$, citrinine (CIT), NEO, DAS, mycophenolic acid (MPA), cyclopiazonic acid (CPA), verruculogen (VER), FB1, FB2, patulin (PAT) and gliotoxin were purchased from Sigma-Aldrich (St. Louis, MO, USA). HPLC grade of acetonitrile and methanol were purchased from Merck (Darmstadt, Germany). Other solvents and chemicals were of HPLC or analytical grade from local suppliers. Deionized water purified by Milli-Q water (Millipore, Billerica, MA, USA) was used throughout the experiments.

\subsection{Molecular Characterization of the Fusarium Strains}

Fusarium strains were molecularly characterized by examining the sequence of the translation elongation factor 1-alpha $(E F-1 \alpha)$ gene, known as one of the most pertinent genes for identification of the Fusarium species [55].

Mycelia plugs from 7-day old potato dextrose agar (PDA) (composition seen in Section 4.3) cultures were transferred to potato dextrose broth (PDB) medium (200 g potato and $20 \mathrm{~g}$ glucose per litre) and incubated while shaking $(100 \mathrm{rpm})$ at $28^{\circ} \mathrm{C}$ in the dark for 5 days. After incubation, the mycelia were harvested by filtration through filtering cloth, freeze-dried and ground to fine powders using a TissueLyser II system (Qiagen Tissuelyser II, Retsch, Haan, Germany).

Genomic DNA of strains was extracted based on the Cetyltriethyl Ammnonium Bromide (CTAB) protocol described by Wang et al. [56]. Portions of the EF-1 $\alpha$ gene were amplified with primers EF1T ( $\left(3^{\prime}\right.$-ATGGGTAAGGAGGACAAGAC-5') and EF2T ( $3^{\prime}$-GGAAGTACCAGTGATCATGTT-5') in a thermal cycler (T100 Thermal Cycler, Bio-Rad, Foster City, CA, USA). Polymerase chain reaction (PCR) amplification was performed using a modified procedure described [57]. PCR reaction mixtures (total volume of $20 \mu \mathrm{L}$ ) contained $80 \mathrm{ng}$ of fungal genomic DNA template, $1 \times$ PCR buffer $(20 \mathrm{mM}$ Tris- $\left.\mathrm{HCl} \mathrm{pH} \mathrm{8.3,} 20 \mathrm{mM} \mathrm{KCl}, 10 \mathrm{mM}\left(\mathrm{NH}_{4}\right)_{2} \mathrm{SO}_{4}, 2 \mathrm{mM} \mathrm{MgSO}_{4}\right)$ (TransGen Biotech, Beijing, China), $0.25 \mathrm{mM}$ deoxynucleoside triphosphate (dNTPs) (Dongsheng Biotech, Guangzhou, China), $2.5 \mathrm{U}$ of Easy Taq DNA polymerase (TransGen Biotech, Beijing, China) and $0.2 \mu \mathrm{M}$ of each primer. The conditions for thermal cycler consisted of an initial denaturation step at $94{ }^{\circ} \mathrm{C}$ for $4 \mathrm{~min}$, followed by 30 cycles of denaturation at $94{ }^{\circ} \mathrm{C}$ for $30 \mathrm{~s}$, annealing at $56^{\circ} \mathrm{C}$ for $40 \mathrm{~s}$ and extension at $72{ }^{\circ} \mathrm{C}$ for $30 \mathrm{~s}$, then a final extension of $72{ }^{\circ} \mathrm{C}$ for $5 \mathrm{~min}$. An aliquot of $8 \mu \mathrm{L}$ of amplified products was separated by electrophoresis onto a $1 \%$ agarose gel, stained with ethidium bromide and photographed under UV light in a Bio-Imaging system (Bio-Rad, Hercules, CA, USA). The incised fragment gels were sent to Invitrogen $^{\mathrm{TM}}$ (Shanghai, China) for sequencing. Then the EF-1 $\alpha$ amplicon sequences (shown in Table S6) generated in this study were compared with sequences available by using the BLAST program [58]. The phylogenetic trees were made using MEGA5.0 for Neighbor-joining (N-J) analysis and the reliability was confirmed by bootstrapping using 1000 random replicates.

\subsection{Preparation of Different Types of Growth Media}

Three typical media including PDA, maize medium and rice medium, were prepared for inoculation and incubation of the Fusarium strains. PDA medium (200 g potato, $20 \mathrm{~g}$ glucose, and 15-20 g agar per litre) was prepared by autoclaving at $121^{\circ} \mathrm{C}$ for $15 \mathrm{~min}$ and then $15 \mathrm{~mL}$ of molten media was poured into $9 \mathrm{~cm}$ diameter sterile Petri dishes. Maize/rice media were prepared by adding $25 \mathrm{~mL}$ deionized water into $50 \mathrm{~g}$ of mycotoxin-free maize/rice samples, vigorously shaken to prevent clumping, maintained overnight and sterilized in an autoclave for $15 \mathrm{~min}$ at $121^{\circ} \mathrm{C}$.

\subsection{Inoculation of the Targeted Fungal Strains}

Prior to the inoculation experiments, each fungal strain was cultured separately on PDA for 7 days at $25{ }^{\circ} \mathrm{C}$ for activation of the strain. The inoculation method was conducted as previously described $[59,60]$ with minor modifications. A piece of $6 \mathrm{~mm}$ diameter agar disc taken from the margin 
of a 7-day old colony of each strain grown on PDA was placed in the centre of each test medium and incubated at $25{ }^{\circ} \mathrm{C}$ for 21 days. Control samples were prepared following the same procedure without fungal inoculation and each treatment was performed in triplicate. After 21 days of incubation, the media were harvested and dried at $40{ }^{\circ} \mathrm{C}-50{ }^{\circ} \mathrm{C}$ until constant weight was achieved, and then finely ground into homogenous powders and stored in the freezer for mycotoxin analysis.

\subsection{Analysis of Multiple Mycotoxins}

The mycotoxins produced by various Fusarium strains were extracted and simultaneously determined by LC-MS/MS covering a total of thirty three frequently occurring mycotoxins, which has been established in the previous studies [61].

\subsection{Statistical Analysis}

A pie chart and a three-dimensional histogram model were plotted using Microsoft Office Excel 2003 (Microsoft Corp., Redmond, WA, USA). Statistical analysis was performed using SPSS statistical package 17.0 (SPSS Inc., Chicago, IL, USA). One-way analysis of variance (ANOVA) was performed to determine the significance of the main factors and their interactions. $p<0.05$ was considered statistically significant. Multivariate analysis was used to perform principal component analysis (PCA) by SIMCA-P software 11.0 (Umetrics, Umea, Sweden).

Supplementary Materials: The following are available online at www.mdpi.com/2072-6651/9/1/6/s1, Figure S1: LC-MS/MS chromatogram of FB1, FB2 and fusaric acid ((a): standards; (b): samples: rice medium, F. proliferatum), Figure S2: LC-MS/MS chromatogram of four type A trichothecenes ((a): standards; (b): samples: rice medium, F. langsethiae), Figure S3: LC-MS/MS chromatogram of five type B trichothecenes ((a): standards; (b): samples: NIV, Fus-X: maize medium, F. poae; DON, ADONs: maize medium, F. graminearum), Figure S4: LC-MS /MS chromatogram of ZEN ((a): standards; (b): samples: rice medium, F. graminearum), Table S1: Relative recoveries of the thirty three targeted mycotoxins at concentration of $50 \mu \mathrm{g} \cdot \mathrm{kg}^{-1}$ spiked in PDA, rice and maize samples using ${ }^{13} \mathrm{C}$-AFB1, ${ }^{13} \mathrm{C}$-OTA, ${ }^{13} \mathrm{C}$-T-2, ${ }^{13} \mathrm{C}$-DON and ${ }^{13} \mathrm{C}-\mathrm{ZEN}$ as the internal standards $(n=5)$, Table S2: Optimum temperatures for mycotoxin production of Fusarium species (PDA, 21 days), Table S3: Mycotoxins profiles of 20 species of toxicogenic Fusarium spp. in PDA medium under culture condition of $25^{\circ} \mathrm{C}$ for 21 days $\left(\mu \mathrm{g} \cdot \mathrm{kg}^{-1}\right)$, Table S4: Mycotoxins profiles of 20 species of toxicogenic Fusarium spp. in rice medium under culture condition of $25^{\circ} \mathrm{C}$ for 21 days $\left(\mu \mathrm{g} \cdot \mathrm{kg}^{-1}\right.$ ), Table S5: Mycotoxins profiles of 20 species of toxicogenic Fusarium spp. in maize medium under culture condition of $25^{\circ} \mathrm{C}$ for 21 days $\left(\mu \mathrm{g} \cdot \mathrm{kg}^{-1}\right)$, Table S6: EF-1 $\alpha$ Sequences of 20 Fusarium species.

Acknowledgments: This work was supported by the National Basic Research Program of China (Grant 2013CB127801), National Natural Science Foundation of China (31471661) and Shanghai Technical Standards Project (15DZ0503800). MUCL (Mycothèque de l'Université catholique de Louvain, Louvain-la-Neuve, Belgium), and in particular François Van Hove and Françoise Munaut are acknowleged for providing some Fusarium strains. We thank Dr. Yuanhong Shan in the Core Facility Centre of the Institute of Plant Physiology and Ecology, Chinese Academy of Sciences for mass spectrometry assistance.

Author Contributions: W.S., Y.T. and S.W. designed and performed the experiments and analyzed the data; W.S., Y.T., Z.W. and A.W. wrote the paper; D.M.G., S.D.S., Y.L., C.W. and Y.F. contributed materials and/or revised the manuscript; A.W. and Z.W. supervised the whole experiments.

Conflicts of Interest: The authors declare no conflict of interest.

\section{References}

1. Duan, C.X.; Qin, Z.H.; Yang, Z.H.; Li, W.X.; Sun, S.L.; Zhu, Z.D.; Wang, X.M. Identification of pathogenic fusarium spp. causing maize ear rot and potential mycotoxin production in China. Toxins 2016, 8. [CrossRef] [PubMed]

2. McMullen, M.P.; Enz, J.; Lukach, J.; Stover, R. Environmental conditions associated with Fusarium head blight epidemics of wheat and barley in the northern great plains, north america. Cereal Res. Commun. 1997, 25, 777-778.

3. Kemp, G.H.J.; Pretorius, Z.A.; Wingfield, M.J. Fusarium glume spot of wheat: A newly recorded mite-associated disease in south africa. Plant Dis. 1996, 80, 48-51. [CrossRef]

4. Gortz, A.; Oerke, E.C.; Steiner, U.; Waalwijk, C.; de Vries, I.; Dehne, H.W. Biodiversity of Fusarium species causing ear rot of maize in Germany. Cereal Res. Commun. 2008, 36, 617-622. [CrossRef] 
5. Covarelli, L.; Stifano, S.; Beccari, G.; Raggi, L.; Lattanzio, V.M.T.; Albertini, E. Characterization of Fusarium verticillioides strains isolated from maize in Italy: Fumonisin production, pathogenicity and genetic variability. Food Microbiol. 2012, 31, 17-24. [CrossRef] [PubMed]

6. McMullen, M.; Bergstrom, G.; De Wolf, E.; Dill-Macky, R.; Hershman, D.; Shaner, G.; Van Sanford, D. A unified effort to fight an enemy of wheat and barley: Fusarium head blight. Plant Dis. 2012, 96, 1712-1728. [CrossRef]

7. Desjardins, A.E.; Plattner, R.D. Fumonisin b(1)-nonproducing strains of Fusarium verticillioides cause maize (zea mays) ear infection and ear rot. J. Agric. Food Chem. 2000, 48, 5773-5780. [CrossRef] [PubMed]

8. Abbas, H.K.; Cartwright, R.D.; Xie, W.; Mirocha, C.J.; Richard, J.L.; Dvorak, T.J.; Sciumbato, G.L.; Shier, W.T. Mycotoxin production by Fusarium proliferatum isolates from rice with Fusarium sheath rot disease. Mycopathologia 1999, 147, 97-104. [CrossRef] [PubMed]

9. Kelly, A.C.; Clear, R.M.; O’Donnell, K.; McCormick, S.; Turkington, T.K.; Tekauz, A.; Gilbert, J.; Kistler, H.C.; Busman, M.; Ward, T.J. Diversity of Fusarium head blight populations and trichothecene toxin types reveals regional differences in pathogen composition and temporal dynamics. Fungal Genet. Biol. 2015, 82, $22-31$. [CrossRef] [PubMed]

10. Bottalico, A.; Perrone, G. Toxigenic Fusarium species and mycotoxins associated with head blight in small-grain cereals in Europe. Eur. J. Plant Pathol. 2002, 108, 611-624. [CrossRef]

11. Tian, Y.; Tan, Y.L.; Liu, N.; Liao, Y.C.; Sun, C.P.; Wang, S.X.; Wu, A.B. Functional agents to biologically control deoxynivalenol contamination in cereal grains. Front. Microbiol. 2016, 7. [CrossRef] [PubMed]

12. Molto, G.A.; Gonzalez, H.H.L.; Resnik, S.L.; Gonzalez, A.P. Production of trichothecenes and zearalenone by isolates of Fusarium spp. from argentinian maize. Food Addit. Contam. 1997, 14, 263-268. [CrossRef] [PubMed]

13. Quarta, A.; Mita, G.; Haidukowski, M.; Santino, A.; Mule, G.; Visconti, A. Assessment of trichothecene chemotypes of Fusarium culmorum occurring in Europe. Food Addit. Contam. 2005, 22, 309-315. [CrossRef] [PubMed]

14. Schollenberger, M.; Muller, H.M.; Rufle, M.; Suchy, S.; Plank, S.; Drochner, W. Natural occurrence of 16 Fusarium toxins in grains and feedstuffs of plant origin from Germany. Mycopathologia 2006, 161, 43-52. [CrossRef] [PubMed]

15. Tian, Y.; Tan, Y.L.; Liu, N.; Yan, Z.; Liao, Y.C.; Chen, J.; De Saeger, S.; Hua, Y.; Zhang, Q.; Wu, A.B. Detoxification of deoxynivalenol via glycosylation represents novel insights on antagonistic activities of trichoderma when confronted with Fusarium graminearum. Toxins 2016, 8. [CrossRef] [PubMed]

16. Sudakin, D.L. Trichothecenes in the environment: Relevance to human health. Toxicol. Lett. 2003, 143, 97-107. [CrossRef]

17. Stoev, S.D. Food safety and increasing hazard of mycotoxin occurrence in foods and feeds. Crit. Rev. Food Sci. 2013, 53, 887-901. [CrossRef] [PubMed]

18. Commission, E. Commission regulation (EC) 1881/2006 of december 19th 2006 replacing regulation (EC) 466/2001 setting maximum levels for certain contaminants in foodstuffs. Off. J. Eur. Commun. 2006, L364, 5-24.

19. The National Food Safety Standard of Maximum Levels of Mycotoxin in Foods (GB 2761-2011). Available online: http://gain.fas.usda.gov/Recent\%20GAIN\%20Publications/Maximum\%20Levels\% 20of\%20Mycotoxins\%20in\%20Foods_Beijing_China\%20-\%20Peoples\%20Republic\%20of_12-29-2014.pdf (accessed on 24 December 2016).

20. Logrieco, A.; Mule, G.; Moretti, A.; Bottalico, A. Toxigenic Fusarium species and mycotoxins associated with maize ear rot in Europe. Eur. J. Plant. Pathol. 2002, 108, 597-609. [CrossRef]

21. van Egmond, H.P.; Schothorst, R.C.; Jonker, M.A. Regulations relating to mycotoxins in food: Perspectives in a global and European context. Anal. Bioanal. Chem. 2007, 389, 147-157. [CrossRef] [PubMed]

22. Bosch, U.; Mirocha, C.J. Toxin production by Fusarium species from sugar-beets and natural occurrence of zearalenone in beets and beet fibers. Appl. Environ. Microb. 1992, 58, 3233-3239.

23. Christ, D.S.; Marlander, B.; Varrelmann, M. Characterization and mycotoxigenic potential of Fusarium species in freshly harvested and stored sugar beet in Europe. Phytopathology 2011, 101, 1330-1337. [CrossRef] [PubMed] 
24. Zhang, J.B.; Li, H.P.; Dang, F.J.; Qu, B.; Xu, Y.B.; Zhao, C.S.; Liao, Y.C. Determination of the trichothecene mycotoxin chemotypes and associated geographical distribution and phylogenetic species of the Fusarium graminearum clade from China. Mycol. Res. 2007, 111, 967-975. [CrossRef] [PubMed]

25. Delgado, J.A.; Schwarz, P.B.; Gillespie, J.; Rivera-Varas, V.V.; Secor, G.A. Trichothecene mycotoxins associated with potato dry rot caused by Fusarium graminearum. Phytopathology 2010, 100, 290-296. [CrossRef] [PubMed]

26. Castillo, M.; Samar, M.; Molto, G.; Resnik, S.; Pacin, A. Trichothecenes and zearalenone production by Fusarium species isolated from argentinean black beans. Mycotoxin Res. 2002, 18, 31-36. [CrossRef] [PubMed]

27. Kokkonen, M.; Ojala, L.; Parikka, P.; Jestoi, M. Mycotoxin production of selected Fusarium species at different culture conditions. Int. J. Food Microbiol. 2010, 143, 17-25. [CrossRef] [PubMed]

28. Llorens, A.; Mateo, R.; Hinojo, M.J.; Valle-Algarra, F.M.; Jimenez, M. Influence of environmental factors on the biosynthesis of type B trichothecenes by isolates of Fusarium spp. from Spanish crops. Int. J. Food Microbiol. 2004, 94, 43-54. [CrossRef] [PubMed]

29. Martins, M.L.; Martins, H.M. Influence of water activity, temperature and incubation time on the simultaneous production of deoxynivalenol and zearalenone in corn (zea mays) by Fusarium graminearum. Food Chem. 2002, 79, 315-318. [CrossRef]

30. Kokkonen, M.; Jestoi, M.; Laitila, A. Mycotoxin production of Fusarium langsethiae and Fusarium sporotrichioides on cereal-based substrates. Mycotoxin Res. 2012, 28, 25-35. [CrossRef] [PubMed]

31. Richard, E.; Heutte, N.; Sage, L.; Pottier, D.; Bouchart, V.; Lebailly, P.; Garon, D. Toxigenic fungi and mycotoxins in mature corn silage. Food Chem. Toxicol. 2007, 45, 2420-2425. [CrossRef] [PubMed]

32. Brzonkalik, K.; Herrling, T.; Syldatk, C.; Neumann, A. The influence of different nitrogen and carbon sources on mycotoxin production in Alternaria alternata. Int. J. Food Microbiol. 2011, 147, 120-126. [CrossRef] [PubMed]

33. Mateo, J.J.; Jimenez, M. Trichothecenes and fumonisins produced in autoclaved tiger nuts by strains of Fusarium sporotrichioides and Fusarium moniliforme. Food Microbiol. 2000, 17, 167-176. [CrossRef]

34. Azira, T.N.; Man, Y.B.C.; Hafidz, R.N.R.M.; Aina, M.A.; Amin, I. Use of principal component analysis for differentiation of gelatine sources based on polypeptide molecular weights. Food Chem. 2014, 151, $286-292$. [CrossRef] [PubMed]

35. Marina, A.M.; Man, Y.B.C.; Amin, I. Use of the saw sensor electronic nose for detecting the adulteration of virgin coconut oil with rbd palm kernel olein. J. Am. Oil Chem. Soc. 2010, 87, 263-270. [CrossRef]

36. Wulff, E.G.; Sorensen, J.L.; Lubeck, M.; Nielsen, K.F.; Thrane, U.; Torp, J. Fusarium spp. Associated with rice bakanae: Ecology, genetic diversity, pathogenicity and toxigenicity. Environ. Microbiol. 2010, 12, 649-657. [CrossRef] [PubMed]

37. Stepien, L.; Koczyk, G.; Waskiewicz, A. Fum cluster divergence in fumonisins-producing Fusarium species. Fungal Biol. 2011, 115, 112-123. [CrossRef] [PubMed]

38. Suga, H.; Kitajima, M.; Nagum, R.; Tsukiboshi, T.; Uegaki, R.; Nakajima, T.; Kushiro, M.; Nakagawa, H.; Shimizu, M.; Kageyama, K.; et al. A single nucleotide polymorphism in the translation elongation factor 1 alpha gene correlates with the ability to produce fumonisin in Japanese Fusarium fujikuroi. Fungal Biol. 2014, 118, 402-412. [CrossRef] [PubMed]

39. Hinojo, M.J.; Medina, A.; Valle-Algarra, F.M.; Gimeno-Adelantado, J.V.; Jimenez, M.; Mateo, R. Fumonisin production in rice cultures of Fusarium verticillioides under different incubation conditions using an optimized analytical method. Food Microbiol. 2006, 23, 119-127. [CrossRef] [PubMed]

40. Ung-Soo, L.; Myong-Yur, L.; Kwang-Sop, S.; Yun-Sik, M.; Chae-Min, C.; Ueno, Y. Production of fumonisin B 1 and $\mathrm{B}_{2}$ by Fusarium moniliforme isolated from Korean corn kerneis for feed. Mycotoxin Res. 1994, 10, 67-72. [CrossRef] [PubMed]

41. Fadl-Allah, E.; Stack, M.; Goth, R.; Bean, G. Production of fumonisins $\mathrm{B}_{1}, \mathrm{~B}_{2}$ and $\mathrm{B}_{3}$ by Fusarium proliferatum isolated from rye grains. Mycotoxin Res. 1997, 13, 43-48. [CrossRef] [PubMed]

42. Leslie, J.F.; Plattner, R.D.; Desjardins, A.E.; Klittich, C.J.R. Fumonisin B 1 production by strains from different mating populations of Gibberella fujikuroi (Fusarium section liseola). Phytopathology 1992, 82, 341-345. [CrossRef]

43. Marasas, W.F.O.; Rheeder, J.P.; Lamprecht, S.C.; Zeller, K.A.; Leslie, J.F. Fusarium andiyazi sp nov., a new species from sorghum. Mycologia 2001, 93, 1203-1210. [CrossRef] 
44. Abramson, D.; Clear, R.M.; Smith, D.M. Trichothecene production by Fusarium spp isolated from manitoba grain. Can. J. Plant Pathol. 1993, 15, 147-152. [CrossRef]

45. Hestbjerg, H.; Nielsen, K.F.; Thrane, U.; Elmholt, S. Production of trichothecenes and other secondary metabolites by Fusarium culmorum and Fusarium equiseti on common laboratory media and a soil organic matter agar: An ecological interpretation. J. Agric. Food Chem. 2002, 50, 7593-7599. [CrossRef] [PubMed]

46. Yli-Mattila, T.; Ward, T.J.; O’Donnell, M.; Proctor, R.H.; Burkin, A.A.; Kononenko, G.P.; Gavrilova, O.P.; Aoki, T.; McCormick, S.P.; Gagkaeva, T.Y. Fusarium sibiricum sp. nov, a novel type a trichothecene-producing Fusarium from Northern Asia closely related to F-sporotrichioides and F-langsethiae. Int. J. Food Microbiol. 2011, 147, 58-68. [CrossRef] [PubMed]

47. Guarro, J.; Rubio, C.; Gene, J.; Cano, J.; Gil, J.; Benito, R.; Moranderia, M.J.; Miguez, E. Case of keratitis caused by an uncommon Fusarium species. J. Clin. Microbiol. 2003, 41, 5823-5826. [CrossRef] [PubMed]

48. Abbas, H.K.; Ocamb, C.M. First report of production of fumonisin B-1 by Fusarium polyphialidicum collected from seeds of Pinus strobus. Plant Dis. 1995, 79, 642. [CrossRef]

49. Thrane, U.; Adler, A.; Clasen, P.E.; Galvano, F.; Langseth, W.; Logrieco, A.; Nielsen, K.F.; Ritieni, A. Diversity in metabolite production by Fusarium langsethiae, Fusarium poae, and Fusarium sporotrichioides. Int. J. Food Microbiol. 2004, 95, 257-266. [CrossRef] [PubMed]

50. Wagacha, J.M.; Muthomi, J.W. Fusarium culmorum: Infection process, mechanisms of mycotoxin production and their role in pathogenesis in wheat. Crop Prot. 2007, 26, 877-885. [CrossRef]

51. Scoz, L.B.; Astolfi, P.; Reartes, D.S.; Schmale, D.G.; Moraes, M.G.; Del Ponte, E.M. Trichothecene mycotoxin genotypes of Fusarium graminearum sensu stricto and Fusarium meridionale in wheat from southern Brazil. Plant Pathol. 2009, 58, 344-351. [CrossRef]

52. Sydenham, E.W.; Marasas, W.F.O.; Thiel, P.G.; Shephard, G.S.; Nieuwenhuis, J.J. Production of mycotoxins by selected Fusarium-graminearum and F-crookwellense isolates. Food Addit. Contam. 1991, 8, 31-41. [CrossRef] [PubMed]

53. Bakan, B.; Pinson, L.; Cahagnier, B.; Melcion, D.; Semon, E.; Richard-Molard, D. Toxigenic potential of Fusarium culmorum strains isolated from French wheat. Food Addit. Contam. 2001, 18, 998-1003. [CrossRef] [PubMed]

54. Burlakoti, R.R.; Ali, S.; Secor, G.A.; Neate, S.M.; McMullen, M.P.; Adhikari, T.B. Comparative mycotoxin profiles of gibberella zeae populations from barley, wheat, potatoes, and sugar beets. Appl. Environ. Microbiol. 2008, 74, 6513-6520. [CrossRef] [PubMed]

55. O'Donnell, K.; Kistler, H.C.; Cigelnik, E.; Ploetz, R.C. Multiple evolutionary origins of the fungus causing panama disease of banana: Concordant evidence from nuclear and mitochondrial gene genealogies. Proc. Natl. Acad. Sci. USA 1998, 95, 2044-2049. [CrossRef] [PubMed]

56. Wang, J.H.; Li, H.P.; Qu, B.; Zhang, J.B.; Huang, T.; Chen, F.F.; Liao, Y.C. Development of a generic pcr detection of 3-acetyldeoxynivalenol-, 15-acetyldeoxynivalenol- and nivalenol-chemotypes of Fusarium graminearum clade. Int. J. Mol. Sci. 2008, 9, 2495-2504. [CrossRef] [PubMed]

57. BLAST program. Avaliable online: https://blast.ncbi.nlm.nih.gov/Blast.cgi (accessed on 5 August 2016).

58. Van Poucke, K.; Monbaliu, S.; Munaut, F.; Heungens, K.; De Saeger, S.; Van Hove, F. Genetic diversity and mycotoxin production of Fusarium lactis species complex isolates from sweet pepper. Int. J. Food Microbiol. 2012, 153, 28-37. [CrossRef] [PubMed]

59. Busko, M.; Chelkowski, J.; Popiel, D.; Perkowski, J. Solid substrate bioassay to evaluate impact of trichoderma on trichothecene mycotoxin production by Fusarium species. J. Sci. Food Agric. 2008, 88, 536-541. [CrossRef]

60. Medina, A.; Magan, N. Temperature and water activity effects on production of T-2 and HT-2 by Fusarium langsethiae strains from north European countries. Food Microbiol. 2011, 28, 392-398. [CrossRef] [PubMed]

61. Han, Z.; Feng, Z.H.; Shi, W.; Zhao, Z.H.; Wu, Y.J.; Wu, A.B. A quick, easy, cheap, effective, rugged, and safe sample pretreatment and liquid chromatography with tandem mass spectrometry method for the simultaneous quantification of 33 mycotoxins in lentinula edodes. J. Sep. Sci. 2014, 37, 1957-1966. [CrossRef] [PubMed]

(C) 2016 by the authors; licensee MDPI, Basel, Switzerland. This article is an open access article distributed under the terms and conditions of the Creative Commons Attribution (CC-BY) license (http:/ / creativecommons.org/licenses/by/4.0/). 